\title{
Depoimento
}

\section{Maria Helena Rolim Capelato}

A ANPHLAC fez 20 anos! O que temos para comemorar?

Uma Associação que começou há duas décadas por iniciativa de um grupo de 15 historiadores reunidos em Mariana (Universidade Federal de Ouro Preto) e hoje conta com a participação de um número expressivo de associados pertencentes a diversas universidades brasileiras, tem muitos motivos para comemorar. A ANPHLAC representa, para todos os que se dedicam à História das Américas, um espaço de debate e divulgação da produção acadêmica na área considerada pelas agências de fomento como "área carente" na época de sua criação. Os encontros bianuais, além da troca de ideias muito produtiva, representam momentos de confraternização de seus membros que se unem a partir de formas diversas de afinidades.

Mas do que adianta uma comemoração sem uma reflexão sobre seu significado? Isso implica uma volta ao pasado. Relembrar o surgimento da Associação nos leva a refletir sobre as motivações que levaram um pequeno grupo a se reunir para propor a sua criação. Na verdade, em 1992, já havia um conjunto significativo de historiadores que se dedicavam ao ensino e/ou pesquisas voltadas para o conhecimento da História da América Latina e do Caribe. Portanto, a ANPHLAC surgiu com o propósito de possibilitar o debate sobre as pesquisas que estavam sendo produzidas na área, estimular a ampliação desses estudos e reivindicar, junto às instituições acadêmicas e agências de fomento, apoio para a realização de pesquisas, sobretudo no exterior, e publicação dos resultados de trabalhos.

Como o texto que apresento tem o objetivo de recuperar a memória da conjuntura que permitiu o surgimento da Associação, iniciarei a exposição apresentando um depoimento pessoal (ou geracional) sobre o passado que representou o início de um grande interesse de alguns setores da sociedade brasileira pela América Latina, até então, menosprezada.

\footnotetext{
* Professora Titular do Departamento de História - FFLCH/USP. E-mail: mhcapelato@ @erra.com.br Revista Eletrônica da ANPHLAC, Dossiê Especial, p. 15-20, jan./jun. 2013. http://revista.anphlac.org.br/index.php/revista
} 
Como me inseria nesse grupo, reporto-me à década de 1960, primeiro momento em que o olhar de muitos brasileiros se voltou para essa parte do Continente de forma positiva.

Nessa primeira fase, ainda na condição de estudante universitária engajada na luta contra a ditadura, o capitalismo e o imperialismo, acompanhei, como muitos outros jovens da minha geração, a construção da sociedade socialista em Cuba e a experiência de governo da Unidade Popular no Chile. O contexto que indicava possibilidade de mudanças na América Latina, provocou um grande entusiasmo por parte de estudantes, intelectuais e artistas. Mas a utopia socialista durou pouco e os obstáculos em relação às transformações que estavam sendo propostas em alguns países logo ficaram evidentes.

Ao invés da nova sociedade, a velha ordem reforçou suas defesas apelando para a instauração de ditaduras militares que tinham como meta impedir o avanço do modelo cubano na região. O novo cenário demonstrava que as forças conservadoras eram muito mais poderosas do que se supunha: a primeira constatação dessa realidade ocorreu a partir do golpe de 1964 e o início de um governo repressor no Brasil; esse governo serviu de modelo para outras experiências similares que ocorreram posteriormente nos demais países do Cone Sul.

O interesse dos jovens da minha geração pela América Latina não esmoreceu nesse momento; continuou alimentado, por um lado, pela vitória da Revolução na Nicarágua e, por outro, pela indignação contra a violência das ditaduras dos países vizinhos. Nessa época, eu vivia na França, onde tinha muito contato com exilados argentinos e chilenos através dos quais chegavam notícias, cada vez mais terríveis, sobre os arbítrios da repressão.

Entre os anos 1960-70, meu olhar para os países da América Latina era essencialmente político; até então, desconhecia a história do Continente mesmo tendo cursado a disciplina de História da América durante a graduação feita no Departamento de História da USP. Como o Catedrático da disciplina colaborava com a ditadura e seus assistentes compartilhavam suas posições políticas e tinham conhecimento limitado da história da disciplina que ministravam, a maioria dos alunos não valorizava a matéria e havia, até mesmo uma certa animosidade em relação a ela por parte dos engajados politicamente, até porque eram perseguidos pelo Catedrático. 
Em meados da década de oitenta o meu olhar para o Continente latinoamericano se modificou, ou melhor, se ampliou por razões acadêmicas. A mudança ocorreu a partir de 1985, quando, já de volta ao Brasil, participei de um concurso no Departamento de História a USP, que resultou na minha contratação para ministrar aulas na disciplina de História da América.

A área já havia passado por uma grande mudança a partir do ingresso de Maria Ligia Prado no Departamento em 1975 que, desde então imprimiu novo direcionamento ao conhecimento da história do nosso Continente; com seu esforço e entusiasmo, conquistou muitos alunos que passaram a se dedicar, sob sua orientação, ao estudo de temas da história latino-americana. Mas no início de suas atividades, os tempos não eram fáceis e a nova mestra teve que enfrentar as resistências da "velha guarda", que permanecia em seus postos; além disso, a sombra da ditadura ainda pairava sobre a Universidade. Dez anos depois, ou seja, quando ingressei na área, a situação era bem diferente.

Quando fui contratada em 1985, ainda estava terminando o doutorado sobre um tema de História do Brasil. Como minha formação era nessa área, somente a partir do final da década me considerei preparada para orientar trabalhos sobre História da América Latina.

Em 1992, quando participei do encontro que resultou na criação da nossa Associação, minha experiência nesse campo historiográfico já era mais sólida e o próprio campo se ampliara consideravelmente.

Então cabe a pergunta: por que a Associação só foi criada na década de 1990 se, desde a década de 1970, o número de historiadores brasileiros que se dedicavam ao ensino e pesquisa na área já aumentara consideravelmente e a produção era significativa?

Acredito que a motivação derivou justamente dessa constatação de que a área se fortalecera. Mas, além disso, o momento era propicio para tal iniciativa porque a atenção de setores mais amplos da sociedade começaram a se voltar para a América Latina numa conjuntura de mudanças importantes que ocorriam no mundo com ampla repercussão nas Américas.

O processo de globalização, que trouxe alterações econômicas profundas nas relações entre os países, sinalizava a necessidade de formação de Blocos Regionais. No 
plano político, as mudanças ocorridas no mundo socialista ("glasnost", "perestroika", queda do "Muro de Berlim"), deram início a um processo de democratização em escala internacional.

Nesse contexto, a América Latina vivia, por um lado, a experiência da redemocratização em países, como o Brasil, governados por regimes ditatoriais, e para estes, o cenário era promissor. No entanto, por outro lado, nessa fase de transição política, essas mesmas sociedades foram afetadas por forte crise econômica e social que colocava em risco a consolidação democrática.

O sociólogo Francisco Weffort escreveu artigos sobre esta questão procurando analisar esse momento de "incerteza" vivido pelas nações latino-americanas, procurando avaliar as possibilidades da consolidação democrática num continente marcado pela enorme desigualdade social e política decorrente da concentração de renda. O grande desafio do período era a conciliação entre democracia ampla com desenvolvimento econômico equilibrado.

A preocupação do autor frente a esse dilema o levou a refletir sobre a problemática da integração regional. Mencionou as dificuldades enfrentadas na transição democrática pelo governo do Uruguai, país empobrecido pela ditadura, e o fracasso do governo de Raul Alfonsín na tentativa de retomada do crescimento na Argentina após a ditadura que arrasou a economia do país. Fez referência também à derrota da democracia no Peru a partir das ações do governo Fujimori e à ameaça de seu desmoronamento na Venezuela, devido ao contraste entre o forte desenvolvimento econômico e a população faminta.

O sociólogo acreditava que a consolidação democrática na região dependia da solução imediata dos problemas econômicos e sociais. Por esse motivo, insistia na necessidade de retomada do crescimento. Como ele, muitos outros analistas da realidade latino-americana do período enfatizavam a ideia de que o crescimento exigia integração econômica e política em âmbito regional. ${ }^{1}$

A tentativa de integração de países da América Latina já vinha sendo feita desde 1960 com a formação da ALALC (Associação Latino Americana de Livre Comércio),

\footnotetext{
${ }^{1}$ WEFFORT, Francisco. Incertezas da transição democrática na América Latina. In: Lua Nova. Revista de Cultura política. Transições políticas na América Latina, n. 16, março 1989, pp. 5-45; A América Errada. Notas sobre a modernidade na América Latina em crise. In: Lua Nova. Integração e Desintegração na América Latina, no. 21, 1990.
} 
criada para fazer frente às dificuldades de intercâmbio comercial entre os países da região no pós-guerra. No final da década, o México e todos os países da América do Sul (com exceção da Colômbia) já integravam o Bloco: os resultados comerciais foram positivos, mas ainda restritos a acordos bilaterais e não multilaterais como fora previsto inicialmente.

Em 1989, teve início um novo processo de integração comercial entre Brasil e Argentina que acabou dando origem ao MERCOSUL.

A formação dos Blocos Econômicos, nessa conjuntura, tinha como meta, não só ao desenvolvimento econômico da América Latina para fazer frente à concorrência da economia globalizada, mas também criar condições para erradicar a miséria e minimizar as desigualdades sociais. No Cone Sul, a alteração desse quadro era mais premente porque disso dependia a consolidação dos processos democráticos ainda vulneráveis às investidas autoritárias.

Com relação ao Brasil, país menos afetado do que seus vizinhos do ponto de vista econômico, mas também com dificuldades de solucionar as disparidades sociais, ocorreu um fenômeno surpreendente: os brasileiros, sempre de olhos voltados para o outro lado do Atlântico ou para o irmão do "Norte", com os quais muitos se identificavam em seus delírios de grandeza, acabou tendo que desviar o olhar para os vizinhos do sul. Isto ocorreu quando, depois de acreditarem nas promessas da ditadura de que o "Gigante adormecido" acordara, tiveram que enfrentar um cenário de grave crise quando o sonho acabou.

O Mercosul contribuiu pouco para a resolução dos problemas brasileiros e das outras nações envolvidas, mas o reconhecimento da dificuldades de reconstrução de um país em novas bases após 20 anos de ditadura, violência política que atingira igualmente Argentina, Uruguai, Paraguai e Chile, acrescida da crise econômica que assolou a região no momento das redemocratizações, sensibilizou parcelas da sociedade brasileira que passaram a admitir similaridades, antes ignoradas ou negadas, em relação às nações com as quais compartilhavam uma origem histórica comum.

Foi nesse contexto que, ainda de forma acanhada, foram ocorrendo iniciativas reveladoras do interesse de intelectuais, políticos, produtores culturais, integrantes de movimentos sociais pela aproximação com os países vizinhos. 
A construção do Memorial da América Latina, em São Paulo, sinalizou uma preocupação do Estado em criar um local que simbolizava a integração latinoamericana.

Na mesma época, também foi criado, no âmbito da Universidade de São Paulo, o PROLAM - Programa de Pós-graduação em Integração da América Latina. Esse Programa surgiu em 1988, com perfil interdisciplinar e foi concebido como um núcleo para o desenvolvimento dos estudos latino-americanos. O objetivo principal era a produção de um conhecimento integrado sobre América Latina com o intuito de fortalecer laços econômicos, políticos, culturais, sociais e científicos entre Brasil, América Hispânica e Caribe.

A equipe de professores que participou da elaboração do projeto de formatação do PROLAM partia da premissa de que a América Latina representava uma unidade diversificada e, portanto, a integração deveria ser pensada levando em conta as semelhanças, mas também as diferenças entre os países que deveriam ser respeitadas e valorizadas.

Nesse contexto, acredito que os historiadores fizeram muito bem o seu trabalho. Através do ensino de História da América e das inúmeras pesquisas realizadas na área, contribuíram para despertar o interesse pelo Continente, não só em relação ao conhecimento do passado, mas também pelas trocas acadêmicas com historiadores dos países da região através da participação em Congressos como os da ANPHLAC.

Vinte anos após seu surgimento, a Associação conta com respeitabilidade nacional e internacional. Portanto, acredito que, comemorar a data e as conquistas de todos esses anos, contribui para renovar o entusiasmo dos que vem se dedicando ao estudo dessa história com grande empenho e interesse.

Muito me emociona a lembrança daquele encontro remoto, razão pela qual apresento este texto no estilo "depoimento pessoal". 